\title{
Genetic dissection of maize phenology using an intraspecific introgression library
}

\author{
Silvio Salvi ${ }^{*}$, Simona Corneti ${ }^{1}$, Massimo Bellotti ${ }^{1}$, Nicola Carraro ${ }^{1,2}$, Maria C Sanguineti ${ }^{1}$, \\ Sara Castelletti ${ }^{1}$, Roberto Tuberosa ${ }^{1}$
}

\begin{abstract}
Background: Collections of nearly isogenic lines where each line carries a delimited portion of a donor source genome into a common recipient genetic background are known as introgression libraries and have already shown to be instrumental for the dissection of quantitative traits. By means of marker-assisted backcrossing, we have produced an introgression library using the extremely early-flowering maize (Zea mays L.) variety Gaspé Flint and the elite line B73 as donor and recipient genotypes, respectively, and utilized this collection to investigate the genetic basis of flowering time and related traits of adaptive and agronomic importance in maize.

Results: The collection includes 75 lines with an average Gaspé Flint introgression length of $43.1 \mathrm{cM}$. The collection was evaluated for flowering time, internode length, number of ears, number of nodes (phytomeres), number of nodes above the ear, number and proportion of nodes below the ear and plant height. Five QTLs for flowering time were mapped, all corresponding to major QTLs for number of nodes. Three additional QTLs for number of nodes were mapped. Besides flowering time, the QTLS for number of nodes drove phenotypic variation for plant height and number of nodes below and above the top ear, but not for internode length. A number of apparently Mendelian-inherited phenotypes were also observed.

Conclusions: While the inheritance of flowering time was dominated by the well-known QTL Vgt1, a number of other important flowering time QTLs were identified and, thanks to the type of plant material here utilized, immediately isogenized and made available for fine mapping. At each flowering time QTL, early flowering correlated with fewer vegetative phytomeres, indicating the latter as a key developmental strategy to adapt the maize crop from the original tropical environment to the northern border of the temperate zone (southern Canada), where Gaspé Flint was originally cultivated. Because of the trait differences between the two parental genotypes, this collection will serve as a permanent source of nearly isogenic materials for multiple studies of QTL analysis and cloning.
\end{abstract}

\section{Background}

The production and the phenotypic analysis of pairs of nearly isogenic lines (NILs) differing only for the allele constitution at given chromosome regions provides the opportunity to test for the presence at such regions of genetic factors involved in the inheritance of a quantitative trait $[1,2]$. In comparison with Quantitative Trait Locus (QTL) analysis carried out based on classical biparental mapping populations such as $F_{2}$, recombinant inbred lines (RILs), etc., this should in principle enhance

\footnotetext{
* Correspondence: silvio.salvi@unibo.it

'Department of Agroenvironmental Sciences and Technologies, University of Bologna, viale Fanin 44, 40127 Bologna, Italy

Full list of author information is available at the end of the article
}

the statistical power of QTL detection by eliminating the blurring effect of multiple, and possibly interacting, segregating QTLs. A collection of NILs, each one differing from a reference recipient genotype for a known limited chromosome region, and altogether representing most of a donor genome, is known as introgression library (IL) [3,4]. In an IL, the donor genome is usually provided by an interfertile accession (usually a landrace or a wild relative), while a breeding elite strain is used as the recipient genetic stock. The process of IL production invariably involves some backcrossing scheme with the assistance of marker surveys during or after the backcross. ILs have been produced for a number of model and crop plant species (Reviewed in [5]; see also
C Biomed Central

() 2011 Salvi et al; licensee BioMed Central Ltd. This is an Open Access article distributed under the terms of the Creative Commons Attribution License (http://creativecommons.org/licenses/by/2.0), which permits unrestricted use, distribution, and reproduction in any medium, provided the original work is properly cited. 
$[6,7])$, and even for model animal species such as mouse [8] and Caenorhabditis [9]. A pair of fully reciprocal IL populations were produced in Arabidopsis [10], with the two accessions used once as donor and once as recipient. One IL was described in maize involving two inbred lines, Tx303 and B73, as donor and recipient genotypes, respectively [11].

An IL enables moving and testing alleles from wild or landraces accessions into the elite gene pool of a crop, thus making possible their exploitation in plant breeding [4]. Accordingly, introgression lines belonging to partial or complete IL were proven to have breeding potential in cotton [12], maize [13], rice [14] and tomato [15]. Additionally, IL lines played a major role in enabling the positional cloning of major QTLs (eg. $[16,17]$ ), by providing the starting plant material where the genetic effect of the target QTL could be followed as any other Mendelian locus.

Here we describe the general features and the initial phenotyping of a maize intraspecific IL obtained using Gaspé Flint as the donor genotype and the elite line B73 as the recipient genotype. Gaspé Flint is a variety belonging to the Northern Flint maize race group [18], which was cultivated by American Native populations in southeastern Canada [19]. It is virtually the earliest known maize genotype and such earliness is the basis of its adaptation to the very short summer growing season of Canada. One of the genetic determinants of Gaspé Flint extreme earliness, the Vegetative to generative transition1 (Vgt1) QTL [20,21] has already been identified by positional cloning and shown to correspond to a noncoding, enhancer-like regulatory element of the AP-2 class transcription factor ZmRap2.7 [22]. The herein described B73 $\times$ Gaspé Flint IL lays the foundations for the genetic and molecular characterization of additional genetic determinants of flowering time and other traits of agronomic and adaptive importance in maize.

\section{Results}

\section{Features and coverage of the introgression library}

The IL was produced following an SSR-based markerassisted backcross procedure (Summarized in Methods) started from the cross B73 $\times$ Gaspé Flint. The genotypic composition of the 75 IL lines is shown in Figure 1A. Among these lines, 66 showed a single introgression, eight showed one additional introgression on a different chromosome and one showed two additional introgressions. The average introgression length, including lines with multiple introgressions, was $43.1 \mathrm{cM}$ per lines (ca. $2.4 \%$ of the maize genome) and ranged between 4.5 and $104.0 \mathrm{cM}$ (Table 1). Most of the lines carried homozygous introgressions, although partial heterozygosity was observed at six lines and total heterozygosity at two lines (ILL35 and ILL69). The majority of the lines carried unique introgressions, with the exception of six pairs of lines (ILL6 and ILL7, ILL43 and ILL44, ILL45 and ILL46, ILL62 and ILL63, ILL67 and ILL68, ILL71 and ILL72), where two lines per region were identified as showing similar introgressions. For each of these pair of lines, the second line was maintained in the IL set because derived from a partially different pedigree (i.e. from different $\mathrm{BC}_{1}-\mathrm{BC}_{4}$ plants) within the IL backcross, implying that the two lines could carry different crossover events at the target introgression or different hidden introgressions. Additional redundancy of Gaspé Flint introgressions was intentionally maintained at bin 8.04-05 (covered by five different lines), bin 3.05-07 (four lines) and bin 9.03-04 (seven lines), which are sites of major flowering time QTLs (see below), in order to provide enhanced opportunities for further genetic investigations. Additional details about IL composition are reported in Table 1.

Among the 173 informative SSR markers, 101 showed a polymorphism between B73 and Gaspé Flint. Although monomorphic and polymorphic SSRs alternated along the chromosomes, regions with contiguous monomorphic SSRs were observed. Such regions hampered the recovery of the corresponding Gaspé Flint chromosome segments. By arbitrarily considering only segments with four or more contiguous monomorphic SSR, we identified six chromosome regions (Table 2), for a total of $220.5 \mathrm{cM}$, corresponding to $12.2 \%$ of the maize reference linkage map (see Methods). Such chromosome portions were technically non-representable within the library genome, at least with the markers used here. Given the low-resolution power of the standard agarose-gel electrophoresis utilized herein, the absence of polymorphism does not necessarily imply identity of nucleotide sequence between Gaspé Flint and B73 at such chromosome regions.

The non-overlapping fraction of the Gaspè Flint genome represented in the library corresponded to 1207.1 cM or to $66.9 \%$ of the maize reference map, which rose to $76.2 \%$ if we only consider the genome portion found polymorphic based on SSR profiles. Table 3 summarizes the IL coverage by chromosome.

With the only aim to support and verify the QTL analysis results based on the IL population, we additionally characterized two small populations, a $\mathrm{BC}_{1}$ (88 plants) and an $F_{2}$ (65 plants) both derived from B73 $\times$ Gaspé Flint crosses (see Methods).

\section{Phenotypic analysis}

Table 4 lists the phenotypic traits (and corresponding acronyms) analysed in this study. As expected, Gaspé Flint showed much lower ND, DPS and PH values (10.7 nodes, 45.0 days and $106 \mathrm{~cm}$, respectively) when compared to B73 (20.2 nodes, 74.7 days and $223 \mathrm{~cm}$ ) (Table 4). 


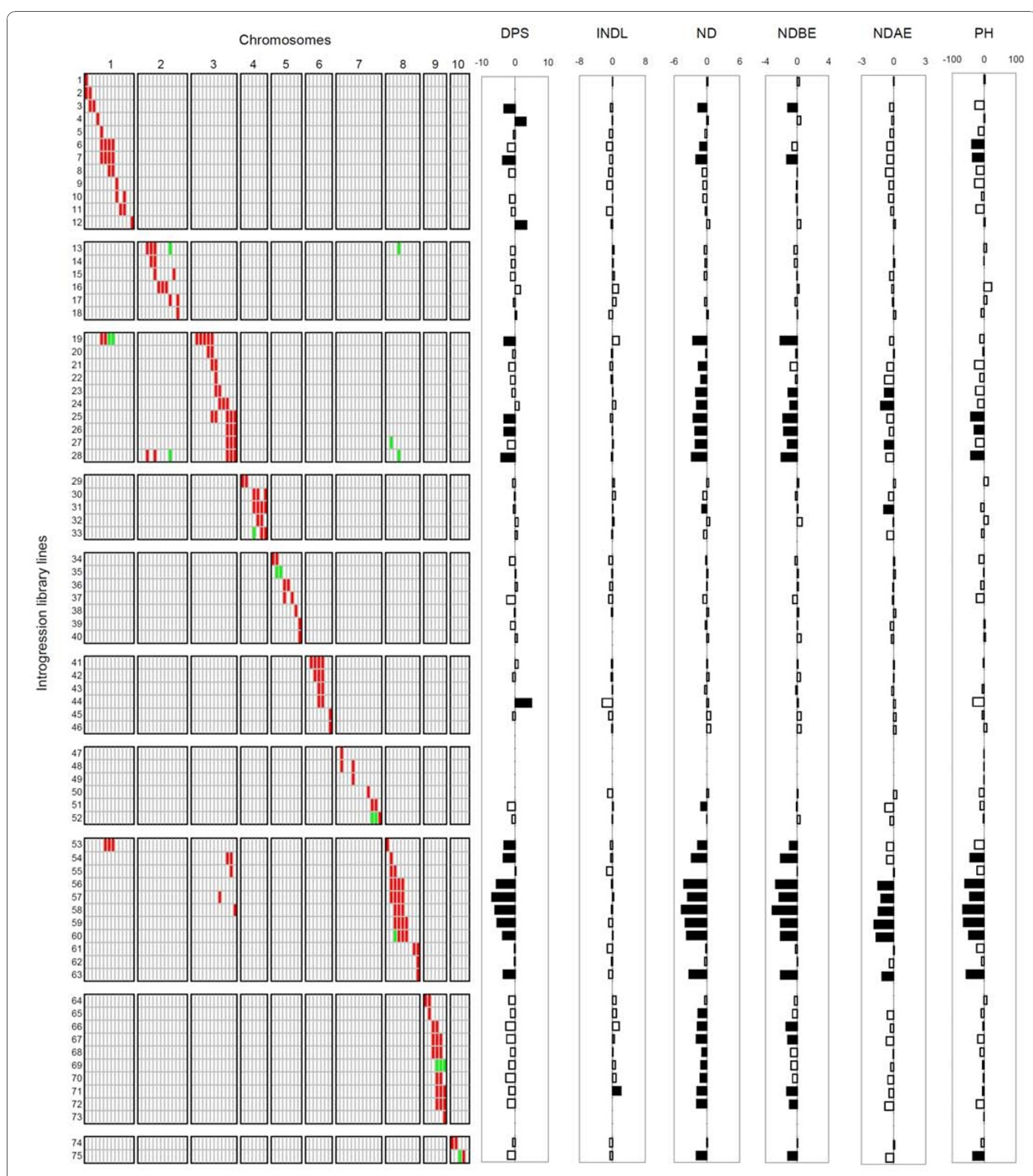

Figure 1 Graphical genotype and QTL effect. (A) Graphical genotype of the B73 × Gaspé Flint introgression library (IL). IL lines are represented horizontally and chromosome positions (polymorphic SSR markers as reported in Figure 2) are indicated vertically. Red and green rectangles indicate homozygous and heterozygous Gaspé Flint introgression, respectively. (B) Phenotypic differences between IL lines and B73, represented as horizontal columns. Black columns indicate IL lines significantly different from B73 $(P<0.05)$. Units are 'no. of days from planting' for days to pollen shed (DPS), 'cm' for internode length (INDL), 'node number' (ND), 'node number' below the top ear (NDBE), 'node number' above the top ear (NDAE) and 'cm' for plant height (PH). 
Table 1 Main features of the B73 $\times$ Gaspé Flint introgression library

\begin{tabular}{|c|c|c|}
\hline IL lines characteristics & & $\begin{array}{l}\% \text { of maize }^{\text {genome }^{a}} \\
\text { gen }\end{array}$ \\
\hline IL lines (No.) & 75 & \\
\hline $\begin{array}{l}\text { Mean length of introgression } \\
\text { in frame }(\mathrm{cM})\end{array}$ & 38.5 & 2.1 \\
\hline $\begin{array}{l}\text { Range of introgression length } \\
\text { 'in frame' }(\mathrm{cM})^{\mathrm{b}}\end{array}$ & $4.5-104.0$ & $0.3-5.8$ \\
\hline $\begin{array}{l}\text { IL lines with completely homozygous } \\
\text { introgression (No.) }\end{array}$ & 68 & \\
\hline $\begin{array}{l}\text { IL lines with partially homozygous } \\
\text { introgression (No.) }\end{array}$ & 6 & \\
\hline $\begin{array}{l}\text { IL lines with completely heterozygous } \\
\text { introgression (No.) }\end{array}$ & 1 & \\
\hline $\begin{array}{l}\text { IL lines with verified additional } \\
\text { introgressions (No.) }\end{array}$ & 9 & \\
\hline $\begin{array}{l}\text { Mean length of verified additional } \\
\text { introgressions (cM) }\end{array}$ & 34.7 & \\
\hline $\begin{array}{l}\text { Mean length of total introgression } \\
\text { per line }(\mathrm{cM})\end{array}$ & 43.1 & 2.4 \\
\hline
\end{tabular}

Additionally, Gaspè Flint showed proportionally lower values for NDAE and NDBE (3.1 and 7.6 nodes) when compared with B73 (6.1 and 14.1 nodes, respectively), and no significant difference was observed for PNDBE. On the other hand, Gaspé Flint showed significantly higher EARN and INDL (3.4 and $15.8 \mathrm{~cm}$ ) than B73 (1.5 ears and 13.8 $\mathrm{cm}$, respectively). The $\mathrm{B} 73 \times$ Gaspé Flint $\mathrm{F}_{1}$ hybrid showed intermediate values between the parental genotypes for all traits except PNDBE for which no significance difference was observed, and for INDL for which it was shown to be significantly $(P<0.01)$ higher than B73 and Gaspé Flint (23.9, 13.8 and 15.8 , cm respectively).

The majority of the IL lines had DPS, GDU, ND, NDBE and PH values close to B73 and only mildly skewed distributions toward the Gaspé Flint values were observed, accordingly with the recovery of most of the

Table 2 Chromosome regions with four or more adjacent monomorphic SSR markers between B73 and Gaspé Flint

\begin{tabular}{cccr}
\hline $\begin{array}{c}\text { Chromosome } \\
\text { bin }\end{array}$ & $\begin{array}{c}\text { Markers included } \\
\text { (No.) }^{\mathbf{a}}\end{array}$ & Marker interval & cM \\
\hline $3.08-3.10$ & 5 & mmc0251-umc2048 & 66.5 \\
$4.02-4.04$ & 8 & umc1294-umc2206 & 30.9 \\
$5.00-5.01$ & 6 & umc1491-umc1781 & 35.2 \\
$6.01-6.02$ & 4 & bnlg1371-phi077 & 34.2 \\
$8.07-8.08$ & 4 & umc2014-umc1384 & 22.0 \\
$9.02-9.03$ & 6 & umc2219-umc1191 & 31.7 \\
\hline & & Total & 220.5 \\
\hline & & Total (\% maize & 12.2 \\
& & genome) & \\
& & &
\end{tabular}

\footnotetext{
${ }^{\mathrm{a}}$ Full markers list is provided in Additional file 6 .
}

Table 3 Chromosome coverage of the B73 $\times$ Gaspé Flint introgression library

\begin{tabular}{cccccc}
\hline Chromosome & Length & Coverage & $\begin{array}{c}\text { Polymorphic } \\
\text { portion }\end{array}$ & $\begin{array}{c}\text { Coverage of } \\
\text { polymorphic } \\
\text { portion } \\
\text { (\%) }\end{array}$ \\
\hline 1 & (cM) & (cM) & (\%) & (\%) & 82.8 \\
2 & 186 & 236.9 & 82.8 & 100.0 & 50.1 \\
3 & 211 & 137.0 & 64.9 & 68.5 & 94.8 \\
4 & 189 & 130.4 & 69.0 & 83.7 & 82.4 \\
5 & 173 & 131.5 & 76.0 & 79.7 & 95.4 \\
6 & 145 & 67.6 & 46.6 & 76.4 & 61.0 \\
7 & 158 & 92.0 & 58.2 & 100.0 & 58.2 \\
8 & 160 & 114.9 & 71.8 & 86.3 & 83.3 \\
9 & 164 & 112.6 & 68.6 & 80.7 & 85.1 \\
10 & 136 & 92.7 & 68.2 & 100.0 & 68.2 \\
\hline Maize genome & 1,805 & & & & \\
\hline Whole IL & \multicolumn{7}{c}{$1,207.1$} & 66.9 & & \\
\hline Homozygous & $1,172.3$ & & \\
introgressions & & & & \\
\hline Heterozygous & & & & \\
introgressions & & & & \\
\hline
\end{tabular}

B73 genome (and therefore QTL alleles) in all lines (Additional file 1). ND, NDAE and NDBE values were non-normally distributed $(P<0.01)$. EARN and ND resulted non-normally distributed in the $\mathrm{BC}_{1}$, similarly to EARN, ND and ND-related traits in the $\mathrm{F}_{2}$.

The $\mathrm{BC}_{1}$ population showed a DPS frequency distribution shifted to lower values when compared with the $\mathrm{F}_{2}$ population (Additional file 1 ). The shift was likely observed because the $\mathrm{BC}_{1}$ population was grown later in the summer, in conditions of higher mean temperatures (not shown). As a confirmation, the shift disappeared when GDU were considered instead of DPS (Additional file 1). The ANOVA (or KruskalWallis test), evidenced significant variation among IL lines $(P<0.001$; not shown $)$ for all traits. Broad sense heritability values ranged between 0.57 for PNDBE to 0.98 for ND (Table 4). Generally, plant (for $\mathrm{F}_{2}$ and $\mathrm{BC}_{1}$ ) or line (for $\mathrm{IL}$ ) values were within parental values and little or no transgressivity was observed for the three populations with the exceptions of $\mathrm{PH}$ and INDL (Additional file 1). For $\mathrm{PH}$ and INDL, transgression was observed in the $\mathrm{F}_{2}$ and $\mathrm{BC}_{1}$ populations, with values higher than the high parent. This type of transgression (beyond the high-value parent) for plant height and related phenotypes is not unexpected given the inherent heterozygosity of $\mathrm{F}_{2}$ and $\mathrm{BC}_{1}$ populations that typically positively influences hybrid vigor. The transgressivity observed in the IL population is specifically treated in the QTL section. 
Table 4 Summary of phenotypic values for B73, F1 B73 × Gaspé Flint and Gaspé Flint, and trait heritability (h2)

\begin{tabular}{|c|c|c|c|c|c|}
\hline Trait & Acronym (unit) & B73 & $F_{1}$ & Gaspé Flint & $h^{2}(\%)^{a}$ \\
\hline Days from planting to pollen shed & DPS (days) & 74.7 & 60.7 & 45.0 & 88.8 \\
\hline Number of ears & EARN (count) & 1.5 & 1.9 & 3.4 & 61.5 \\
\hline Growing degree unit & GDU (unit) & 646 & 458 & 313 & 89.1 \\
\hline Internode length & INDL (cm) & 13.8 & 23.9 & 15.8 & 75.3 \\
\hline Number of nodes & ND (count) & 20.2 & 12.1 & 10.7 & 98.2 \\
\hline Number of nodes above the top ear & NDAE (count) & 6.1 & 4.4 & 3.1 & 88.0 \\
\hline Number of nodes below the top ear & NDBE (count) & 14.1 & 7.7 & 7.6 & 95.9 \\
\hline Plant height & $\mathrm{PH}(\mathrm{cm})$ & 223.3 & 193.8 & 106.0 & 92.1 \\
\hline Proportion of nodes below the top ear & PNDBE (rate) & 0.7 & 0.6 & 0.7 & 57.0 \\
\hline
\end{tabular}

${ }^{a}$ Computed based on the introgression library field experiment.

\section{Correlation among traits}

Across the three populations, ND was strongly positively correlated with NDBE, NDAE, DPS and PH. Additionally, ND was negatively correlated with INDL in the $F_{2}$ and $\mathrm{BC}_{1}$ populations, while this correlation was not significant within the IL (Table 5 and Additional files 2 and 3). GDU and DPS were highly correlated ( $r=0.99$ ). $\mathrm{PH}$ was correlated (positively) with all traits except EARN and PNDBE. The genotypic and phenotypic correlation matrices based on the IL experiment provided almost identical results (Table 5).

\section{QTLs for flowering time}

Eight ND QTLs, on bins 1.02/3, 1.05/6, 3.03, 3.05/7, $4.04 / 5,8.05,9.03 / 4$, and $10.04 / 5$ were identified. In all cases, the direction of the genetic effect of ND and DPS QTLs was univocal, as previously noted for the wellcharacterized flowering time QTLs Vgt1 and Vgt2 [20-22], and in other studies [23]. This prompted us to name these flowering time loci as $q V g t$, followed by the bin number of their map location, with the exception of the QTLs on bins 8.04 and 8.05, for which we kept the former $V g t 1$ and $V g t 2$ acronyms. Summaries of QTL parameters and positions are provided in Table 6, Additional files 4 and 5, and Figure 2. A visualization of the phenotypic differences between each IL line and B73 is provided in Figure $1 \mathrm{~B}$.

The strongest QTL was identified at bin 8.04-8.05 in the IL, $\mathrm{F}_{2}$ and $\mathrm{BC}_{1}$ populations, accordingly with the known position of $V g t 1$ and $V g t 2$ [20]. The additive effect $\left(\mathrm{a}_{\mathrm{i}}\right.$, with $\mathrm{i}=\mathrm{IL}$ or $\left.\mathrm{F}_{2}\right)$ attributed to Vgt1-Vgt2 complex locus in this study was estimated as $\mathrm{a}_{\mathrm{IL}}=-2.0$ and $\mathrm{a}_{\mathrm{F} 2}=-1.5$ nodes (sign indicates direction of effect induced by a Gaspé Flint allele). The Gaspé allele showed partial dominance. The Vgt1-Vgt2 region showed additional effects on DPS, NDBE, NDAE, and $\mathrm{PH}$ in the IL, on NDBE, DPS, and $\mathrm{PH}$ in the $\mathrm{F}_{2}$, and on DPS and $\mathrm{PH}$ in the $\mathrm{BC}_{1}$.

The second strongest effect QTL was $q V g t-3.05 / 7\left(\mathrm{a}_{\mathrm{IL}}=\right.$ -1.1). Additional significant effects were recorded for DPS, NDBE, NDAE, and PH. On the same chromosome, we identified $q V g t-3.03\left(\mathrm{a}_{\mathrm{IL}}=-0.7\right)$. The $\mathrm{BC}_{1} \mathrm{QTL}$ analysis confirmed the presence of flowering time QTL(s) on chr. 3, although the small population size likely precluded the clear separation of LOD peaks.

Two QTLs, $q V g t-1.02 / 3$ and $q V g t-1.05 / 6$, were identified on chr. 1. Such QTLs showed similar genetic effects for $\mathrm{ND}\left(\mathrm{a}_{\mathrm{IL}}=\mathrm{ca} .-0.8\right.$ and -0.9 nodes, respectively) and the same effect for DPS ( $\mathrm{a}_{\mathrm{IL}}=\mathrm{ca},-1.6$ days). The $\mathrm{F}_{2}$ LOD profiles indicated the presence of small effect QTLs for

Table 5 Genotypic (above diagonal) and phenotypic (below diagonal) correlations between traits based on the B73 $\times$ Gaspé Flint introgression library

\begin{tabular}{|c|c|c|c|c|c|c|c|c|c|}
\hline & EARN & DPS & GDU & INDL & ND & NDAE & NDBE & $\mathrm{PH}$ & PNDBE \\
\hline EARN & - & 0.10 & 0.09 & 0.01 & 0.10 & -0.02 & $0.23^{*}$ & 0.14 & $0.44^{*}$ \\
\hline DPS & 0.07 & - & $0.99 * *$ & -0.09 & $0.89^{* *}$ & $0.78^{* *}$ & $0.91^{* *}$ & $0.71^{* *}$ & 0.18 \\
\hline GDU & 0.07 & $0.99^{* *}$ & - & -0.08 & $0.89^{* *}$ & $0.78^{* *}$ & $0.91^{* *}$ & $0.71^{* *}$ & 0.17 \\
\hline INDL & -0.06 & -0.10 & -0.09 & - & -0.11 & 0.01 & -0.09 & $0.40^{* *}$ & -0.18 \\
\hline ND & 0.08 & $0.82^{* *}$ & $0.83^{* *}$ & -0.13 & - & $0.92^{* *}$ & $0.98^{* *}$ & $0.86^{* *}$ & -0.11 \\
\hline NDAE & -0.10 & $0.65^{* *}$ & $0.66^{* *}$ & -0.09 & $0.88^{* *}$ & - & $0.84^{* *}$ & $0.81^{* *}$ & $-0.34^{*}$ \\
\hline NDBE & 0.17 & $0.83^{* *}$ & $0.83^{* *}$ & -0.14 & $0.97^{* *}$ & $0.73^{* *}$ & - & $0.83^{* *}$ & $0.23^{*}$ \\
\hline $\mathrm{PH}$ & 0.06 & $0.66^{* *}$ & $0.66^{* *}$ & $0.46^{* *}$ & $0.82^{* *}$ & $0.72^{* *}$ & $0.79^{* *}$ & - & -0.02 \\
\hline PNDBE & $0.35^{* *}$ & -0.03 & -0.03 & -0.04 & -0.19 & $-0.64^{* *}$ & 0.05 & -0.17 & - \\
\hline
\end{tabular}

*,*: significance at $P 0.05$ and 0.01 , respectively. 
Table 6 Features of the QTLs identified in the B73 $\times$ Gaspé Flint introgression library

\begin{tabular}{|c|c|c|c|c|c|c|}
\hline Trait & $\mathrm{QTL}^{\mathrm{a}}$ & Bin & $c M^{b}$ & Marker interval $^{c}$ & Effect $^{d}$ & $P$ \\
\hline \multirow[t]{5}{*}{ DPS } & & $1.02-03$ & $25.8-69.6$ & bnlg1007 & -1.6 & 0.01 \\
\hline & & $1.05-06$ & $108.7-134.0$ & umc1395 & -1.6 & 0.001 \\
\hline & & $3.05-07$ & $69.2-144.5$ & umc1167-umc1528 & -1.5 & 0.001 \\
\hline & & 8.05 & $70.7-91.6$ & vgt1-umc1846 & -2.4 & 0.001 \\
\hline & & $9.03-04$ & $59.2-82.4$ & umc1271-umc1771 & -1.1 & 0.001 \\
\hline \multirow[t]{5}{*}{ GDU } & & $1.02-03$ & $25.8-69.6$ & bnlg1007 & -21.1 & 0.01 \\
\hline & & $1.05-06$ & $108.7-134.0$ & umc1395 & -20.6 & 0.001 \\
\hline & & $3.05-07$ & $69.2-144.5$ & umc1167-umc1528 & -17.8 & 0.001 \\
\hline & & 8.05 & $70.7-91.6$ & vgt1-umc1846 & -33.3 & 0.001 \\
\hline & & $9.03-04$ & $59.2-82.4$ & umc1271-umc1771 & -13.5 & 0.001 \\
\hline INDL & & $9.03-04$ & $59.2-82.4$ & umc1271-umc1771 & 0.5 & ns $(0.10)$ \\
\hline \multirow[t]{8}{*}{$\mathrm{ND}$} & qVgt-1.02/3 & $1.02-03$ & $25.8-69.6$ & bnlg1007 & -0.8 & 0.001 \\
\hline & qVgt-1.05/6 & $1.05-06$ & $108.7-134.0$ & umc1395 & -0.9 & 0.001 \\
\hline & qVgt-3.03 & 3.03 & $36.1-49.2$ & umc1030 & -0.7 & 0.01 \\
\hline & qVgt-3.05/7 & $3.05-07$ & $69.2-144.5$ & umc1167-umc1528 & -1.1 & 0.001 \\
\hline & qVgt-4.04/5 & 4.04-05 & $58.8-82.6$ & bnlg490-bnlg1265 & -0.4 & 0.05 \\
\hline & Vgt1-Vgt2 & 8.05 & $70.7-91.6$ & vgt7-umc1846 & -2.0 & 0.001 \\
\hline & qVgt-9.03/4 & $9.03-04$ & $59.2-82.4$ & umc1271-umc1771 & -0.7 & 0.001 \\
\hline & qVgt-10.04/5 & $10.04-05$ & $43.8-97.7$ & umc2163-bnlg1250 & -1.0 & 0.001 \\
\hline \multirow[t]{3}{*}{ NDAE } & & $4.04-05$ & $58.8-82.6$ & bnlg490-bnlg1265 & -0.3 & 0.05 \\
\hline & & $3.05-07$ & $69.2-144.5$ & umc1167-umc1528 & -0.3 & 0.05 \\
\hline & & 8.05 & $70.7-91.6$ & vgt7-umc1846 & -0.8 & 0.001 \\
\hline \multirow[t]{6}{*}{ NDBE } & & $1.02-03$ & $25.8-69.6$ & bnlg1007 & -0.6 & 0.01 \\
\hline & & $1.05-06$ & $108.7-134.0$ & umc1395 & -0.5 & 0.01 \\
\hline & & $3.05-07$ & $69.2-144.5$ & umc1167-umc1528 & -0.7 & 0.001 \\
\hline & & 8.05 & $70.7-91.6$ & vgt1-umc1846 & -1.1 & 0.001 \\
\hline & & $9.03-04$ & $59.2-82.4$ & umc1271-umc1771 & -0.5 & 0.01 \\
\hline & & 10.04-05 & $43.8-97.7$ & umc2163-bnlg1250 & -0.6 & 0.01 \\
\hline \multirow[t]{4}{*}{$\mathrm{PH}$} & & $1.05-06$ & $108.7-134.0$ & umc1395 & -17.4 & 0.01 \\
\hline & & $3.05-07$ & $69.2-144.5$ & umc1167-umc1528 & -14.0 & 0.05 \\
\hline & & 8.05 & $70.7-91.6$ & vgt7-umc1846 & -26.0 & 0.001 \\
\hline & & $10.04-05$ & $43.8-97.7$ & umc2163-bnlg1250 & -17.4 & 0.01 \\
\hline
\end{tabular}

${ }^{a}$ QTL codes are given for the trait ND only (see text).

b Position of the QTLs based on the Gaspé Flint introgressions position and length, as estimated on the reference maize map "Genetics 2008" http://www. maizegdb.org/map.php.

' Markers or marker-intervals delimiting the Gaspé Flint introgressions at the QTL chromosome regions.

${ }^{d}$ QTL genetic effects computed as (ILLs - B73)/2, where ILLs is the trait mean value of all IL lines sharing the same introgression at the QTL region.

DPS at bin 1.02/3 and for PH at bin 1.05/6. The QTL analysis on $\mathrm{BC}_{1}$ identified a DPS QTL at an intermediate position between the two previous locations.

One QTL was identified on chr. 4 (qVgt-4.04/5) with $\mathrm{a}_{\mathrm{IL}}=-0.4$ nodes. An ND QTL peak (although at sub-significance level, $\mathrm{LOD}$ peak $=2.6$, threshold at $\mathrm{LOD}=2.8$ ) was identified at the same position in the $\mathrm{BC}_{1}$ population.

One QTL, $q V g t-9.03 / 4$, with $\mathrm{a}_{\mathrm{IL}}=-0.7$ nodes was identified on chr. 9. The IL lines sharing similar chr. 9 introgressions showed a consistent although not significant effect on DPS as well. The presence of a QTL was confirmed by significant ND and NDBE LOD peaks and a consistent DPS LOD profile in the $F_{2}$ population while the $\mathrm{BC}_{1}$ map did not properly cover this chromosome region.

On chr. 10, the qVgt-10.04/5 QTL was detected with a rather conspicuous additive genetic effect $\left(\mathrm{a}_{\mathrm{IL}}=-1.0\right.$ nodes) and with correlated effects on NDBE and PH and just below significance on DPS (not shown). Confirmation of map location was obtained with the $\mathrm{F}_{2} \mathrm{QTL}$ analysis for ND, DPS, NDBE, NDAE and PH. No QTL was identified in this region in the $\mathrm{BC}_{1}$ population probably because of the reduced effect of the QTL in the $\mathrm{BC}_{1}$, since the $\mathrm{B} 73$ alleles showed partial dominance (at least for DPS, NDBE and NDAE). Alternatively, this QTL could be particularly sensitive to environmental 


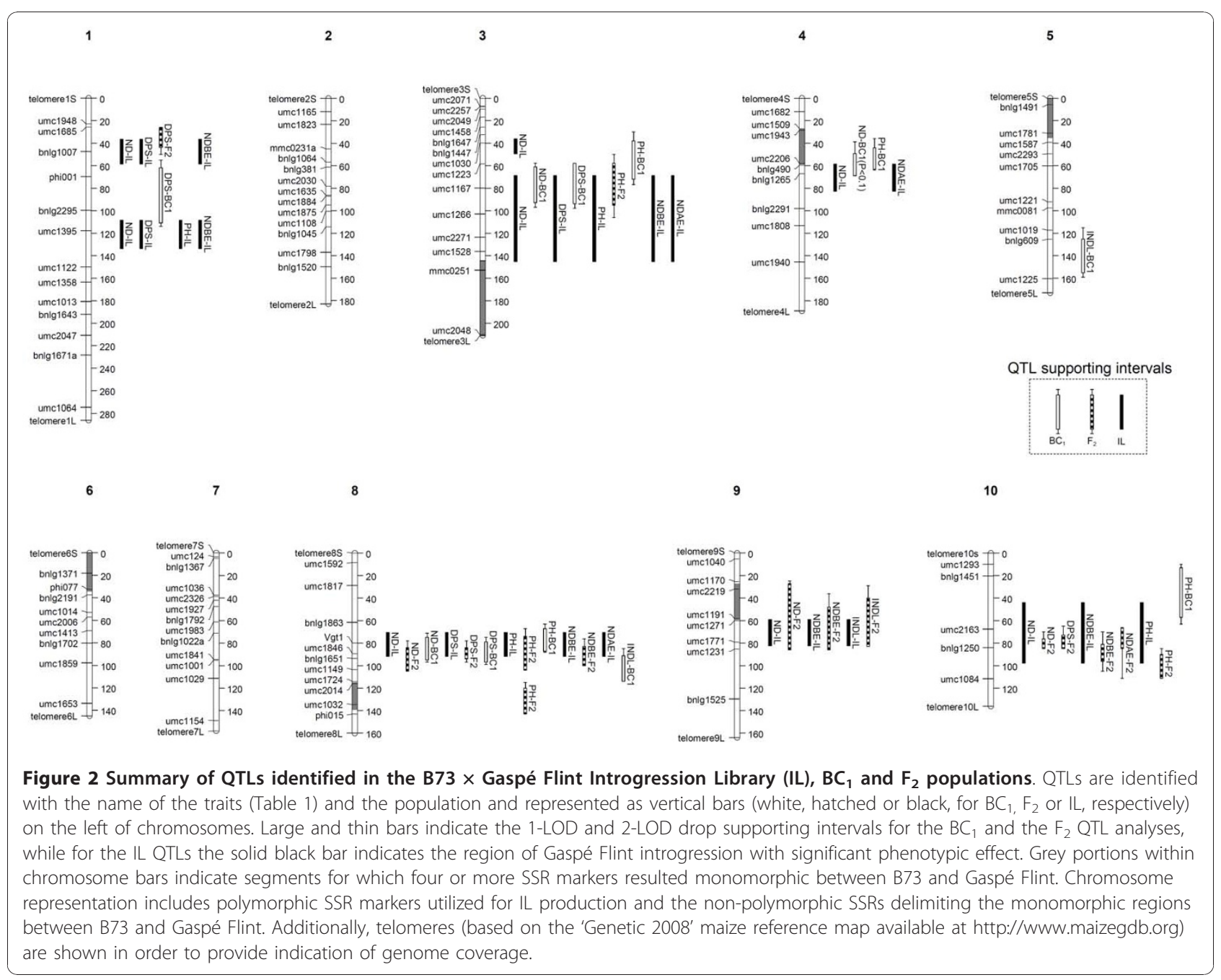

cues, since the $\mathrm{BC}_{1}$ population was grown in a different year as compared to the IL and the $\mathrm{F}_{2}$, and with a late planting date. Interestingly, a QTL for photoperiod sensitivity was mapped right at bin 10.04 in several other studies [24-26].

The results of the QTL analysis for GDU were virtually equivalent to those for DPS (Table 6) and will not be discussed further.

Other IL lines showing remarkable flowering phenotypes A limited number of IL lines, namely ILL4, ILL12, ILL44, ILL51 and ILL63 (Figure 1B), showed flowering timerelated phenotypes and yet their introgressed regions were not considered in the QTL summary because of lack of further experimental evidence from other lines or lack of coincidence with the $\mathrm{F}_{2}$ and the $\mathrm{BC}_{1}$ results. It should be noted that ILL4, ILL12 and ILL44, while not showing any ND change when compared to B73, flowered significantly later than the latter. Such subtle effect likely went undetected in the $\mathrm{BC}_{1}$ and $\mathrm{F}_{2}$ populations.

\section{QTLs for other traits}

In keeping with the high phenotypic and genotypic correlation values, lines showing an effect on ND almost invariably influenced NDBE, with the only exception being the two minor QTLs qVgt-3.03 and qVgt-4.04/5. A similar trend was observed for NDAE, although in this case only three Vgt QTLs reached significance. The $\mathrm{F}_{2}$ QTL analysis confirmed the effects of $V g t$ QTLs on NDBE and NDBE, albeit at fewer QTLs, in accordance with the lower detection power of the $F_{2}$ experiment.

The Gaspé Flint introgressions corresponding to $q \mathrm{Vgt}$ 1.05/6, qVgt-3.05/7, Vgt1-Vgt2 and qVgt-10.04/5 significantly affected PH within the IL, with the Gaspé allele reducing $\mathrm{PH}$. Additionally, $\mathrm{PH}$ mean values were similarly reduced, albeit not significantly, by the Gaspé allele at the other $q$ Vgts. The analyses of the $\mathrm{F}_{2}$ and $\mathrm{BC}_{1}$ identified two additional PH QTLs, at bins 8.06/8 and 10.01/ 4, respectively, which did not correspond to any $q$ Vgts. For the latter QTL, Gaspé Flint provided the allele with the positive effect. 
One line (ILL71, bin 9.03/4) showed a significant effect on INDL, with the Gaspé Flint allele increasing the trait value $\left(\mathrm{a}_{\mathrm{IL}}=1.0 \mathrm{~cm} ; P<0.05\right)$. Additionally, all other lines carrying introgressions at the same bin (corresponding to $q$ Vgt-9.03/4) showed a concordant direction of genetic effect $\left(\mathrm{a}_{\mathrm{IL}}=0.5 \mathrm{~cm} ; P<0.10\right)$. The presence of the INDL QTL was confirmed in the $\mathrm{F}_{2}\left(\mathrm{a}_{\mathrm{F} 2}=2.1 \mathrm{~cm}\right)$. The lack of any detectable effect on $\mathrm{PH}$ at this chromosome region is probably caused by the balancing effect on $\mathrm{PH}$ due to a decrease of ND with a contemporary increase of INDL. Minor effect INDL QTLs were identified at bins 5.06/8 and $8.05 / 7$ in the $\mathrm{BC}_{1}$, with Gaspé Flint providing the positive allele in both cases.

No EARN and PNDBE QTLs were detected in the three populations.

\section{IL lines with multiple $\mathbf{V g t}$ introgressions}

A number of IL lines were identified with trait values significantly different from B73 and carrying multiple introgressed Vgt QTLs. While their phenotypic values were not utilized to estimate the QTL effects, such lines are potentially useful for downstream analyses of QTL interaction or for marker-assisted applications. Examples of such lines are ILL25 (introgressions at qVgt-3.03 and $q$ Vgt-3.05/7), ILL28, ILL54, ILL55 and ILL57 (introgressions at $q$ Vgt-3.05/7 and Vgt1).

\section{Qualitative traits}

A number of clearly qualitative phenotypes segregated within the IL. A locus (here tentatively named Field kernel cracking, $F k c$ ) was found to influence the cracking (popping) of the kernel on the maturing ear (Figure 3A) and shown to map at bin 1.04 as confirmed by four IL lines carrying overlapping Gaspè Flint introgressions. A locus responsible for the presence of a pigmented red band on the tassel outer glumes (which we tentatively named Red band on glumes, Rbg) was confirmed by three IL lines carrying overlapping introgressions at bin 2.03/4 (Figure 3B). Other IL lines showed clear distinct phenotypes (Glossy for ILL63, White stripes for ILL72, Zebra crossbands for ILL14. Figure 3C-E). However, because each phenotype was observed based on one IL line only, the attribution of these loci to a given chromosome region remains uncertain. We further observed ILL4 as the only IL line with white cobs whereas all other lines and B73 had red cobs (not shown). This is in accordance with ILL4 introgression at bin 1.03 encompassing the $p 1$ locus, known to provide pigmentation of the soft floral parts of the cob [27].

\section{Discussion}

\section{Genetic basis of flowering time in maize}

The molecular dissection of quantitative traits is moving quickly from QTL to trait mapping, which is not only mapping and cloning one or few QTLs but rather the identification of all the major components responsible for the genetic variability of a given trait in a crop species. Buckler and co-workers [28], using the nested-association mapping approach identified ca. 50 QTLs for flowering time at relatively high-resolution. However, even if such QTL map information can now be linked directly to the maize genome sequence [29] and thus to candidate genes, the identification of the causal genes or sequence features (also known as quantitative trait nucleotides - QTN [30]) remains unsolved, and will still require the development of targeted cross populations for positional cloning.

The IL lines and the QTL results described here provide a starting point for the positional cloning of seven additional flowering time QTLs, similarly to what has been achieved for Vgt1. Although the genetic effects estimated for these $V g t$ loci were considerably smaller than the Vgt1 one (ca. a =1.8 ND [22]), the Mendelization of even the smallest effect QTL ( $q$ Vgt-4.04/5, a = 0.4 ND), assuming a single causal gene per locus, could be obtained by phenotyping the segmental nearly-isogenic lines for ND based on a low level of replication (ca. three, on an eight-plant plot basis).

The full genetic dissection of the phenotypic differences between B73 and Gaspé Flint undoubtedly suffered by the incomplete coverage of the Gaspé Flint genome (ca 70\%) and by the partial genotyping. The incomplete coverage could have prevented the identification of additional flowering time QTLs while the partial genotyping could have precluded the identification of multiple introgressions within IL lines. The latter situation could have lead to both false positive (the effect was wrongly attributed to an introgressed chromosome region while it was actually due to a QTL laying into a hidden introgression) and false negative (the effect of an identified introgression was counterbalanced by the effect of a hidden one), or more generally to biased estimation of effects. Such drawbacks were at least partially prevented by carrying out parallel QTL analyses on the $\mathrm{B} 73 \times$ Gaspé Flint-derived $\mathrm{BC}_{1}$ and $\mathrm{F}_{2}$ populations. In this regard, the comparison of the results of the QTL analyses from the three populations showed that all flowering time QTLs (in terms of ND and DPS) highlighted within the $\mathrm{BC}_{1}$ and the $\mathrm{F}_{2}$ populations were identified in the analysis of the IL. Such QTLs were the strongest in terms of genetic effect estimated in the IL, making unlikely that additional major QTLs went unnoticed within the IL.

Several important biological questions can be addressed based on the availability of this IL. As previously observed $[20,23]$, we confirmed a high correlation between ND and DPS. Such correlation was also evident if direction and intensity of gene effect at the 


\section{A}

\section{Field kernel cracking - Fkc (bin1.04)}

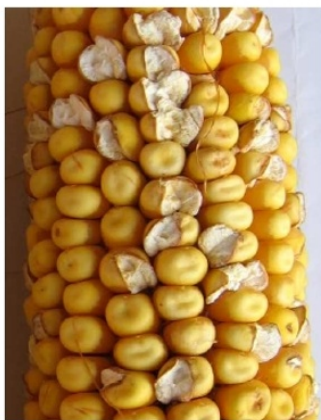

ILL5, ILL6, ILL7 and

ILL19

B

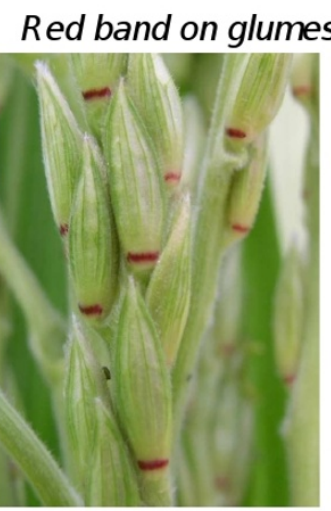

ILL13, ILL14 and

ILL15

C

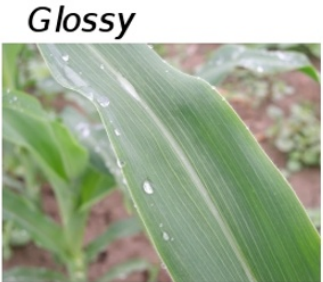

ILL63

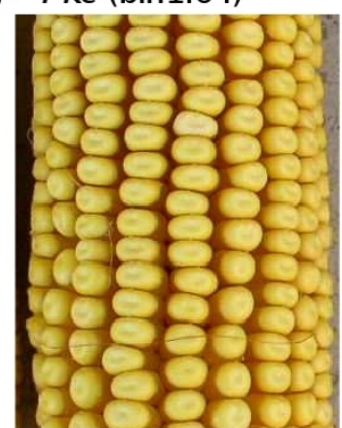

B73

\section{$-R b g(\operatorname{bin} 2.03 / 4)$}

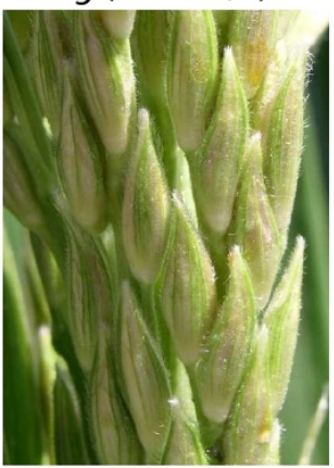

B73

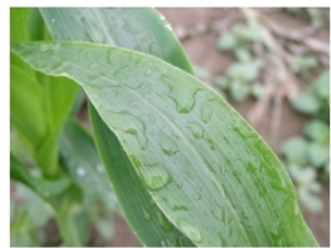

B73

D

White stripes

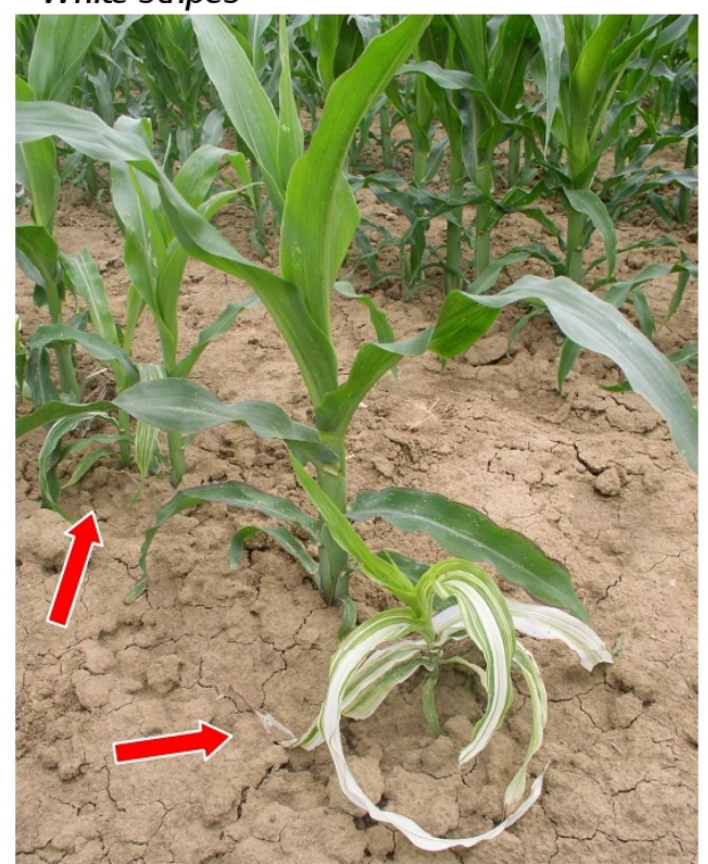

Segregation within ILL72

E

Zebra crossbands

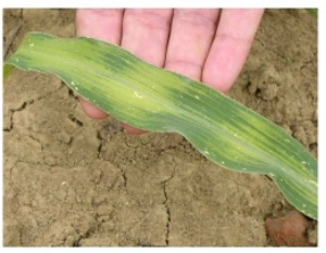

ILL14

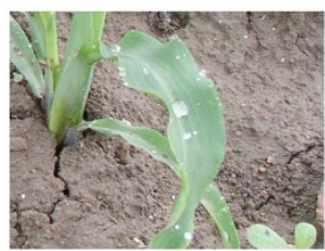

B73

Figure 3 Qualitative phenotypes observed within the $\mathbf{B} 73 \times$ Gaspé Flint introgression library. (A) to (C) and (E): qualitative phenotypes as shown by relevant IL lines and comparison with B73 (right of each pair of images). (D): IL line plot showing phenotypic segregation with mutant/altered and wild-type plants.

DPS and ND QTL are considered (Table 6). Correlation between two traits paralleled by the coincidence of QTLs and concurrent direction of QTL genetic effects have been recognized as indications of prevalent pleiotropy [31]. In our case, the causative QTNs at the flowering time QTLs would influence both ND and DPS. Because of the developmental architecture of cereals, this translates in allele variation influencing primarily ND and consequently DPS. However, linkage of different genes for ND and DPS at some of the flowering time QTLs cannot be excluded until molecular cloning of these QTLs will be accomplished. Additionally, we showed that QTLs for DPS were fewer than QTLs for ND and that QTLs for DPS coincided with QTLs for 
ND. Such observations imply that allelic variation at genes influencing the time of switch to the reproductive phase prevails over genetic variation for the rate of development (both plastochron and/or phyllochron, that is, the rate of phytomere differentiation and distension, respectively). Accordingly, genes known to be involved in maize plastochron (corngrass1/mir156 mapped on chr. 3, at 24.4 cM and PLA3/Vp8, mapped on chr. 1, at $243 \mathrm{cM}[32,33])$ map outside the confidence interval of the Vgt QTLs. The lack of any QTL involved in plastochron/phyllochron is puzzling. Perhaps strong allelic variation for plastochron/phyllochron genes is not compatible with extreme earliness and satisfactory crop production, in such a way that strong plastochron/ phyllochron new early alleles were (are) eliminated unconsciously during the domestication and/or the breeding processes. Alternatively, in the early phases of maize domestication and expansion, variation at such genes (at least between B73 and Gaspé Flint) was lost. It is noteworthy that three lines (ILL4, ILL12, and ILL44) were identified that showed delayed DPS without significant effect on ND. Unfortunately, the existence of such QTLs was not corroborated by multiple IL lines and by the $\mathrm{BC}_{1}$ and $\mathrm{F}_{2}$ QTL results. For these lines, the Gaspé Flint allele contributed the late allele. Altogether, the existence of Gaspé Flint alleles delaying DPS without affecting ND cannot be completely excluded. The observed delay in flowering time could result from i) a general slow plant development or ii) specific delay of tassel and/or flower development and anther extrusion.

As expected and previously observed [23], ND variation also tightly drove variation for $\mathrm{PH}$ (the more numerous the phytomeres, the higher the plant) and NDBE (if apical dominance is constant or independently controlled from ND, a change in ND will directly reflect to NDBE). Unexpectedly, ND variation (and therefore $V g t$ QTLs) also correlated with NDAE, with the ND vs. NDAE phenotypic correlation $r=0.88(P<0.01)$ (Table $5)$. One explanation is that NDAE (therefore the extension of the apical dominance signal) is related to plant height by the presence of a root- or crown-originated acropetal promoting-signal counterbalancing the apical dominance basipetally driven by auxin [34]. Alternatively, co-segregation for QTLs influencing apical dominance along with flowering time is possible. As a matter of fact, the NDAE effect detected in this study at bin 3.05/7 coincides with a QTL previously reported for the same trait [23,35], and a well-supported candidate gene (barren stalk1 [36]). Additionally, the Lfy locus, influencing the number of leaves above the ear [37], maps on 3L [27].

Only bin 9.02/4 consistently showed an effect on INDL, based on IL and $F_{2}$ QTL analyses. Interestingly, the gene Dwarf3, that codes for a P-450 cytochrome involved in gibberelline biosynthetic pathway [38] maps within such interval.

$\mathrm{PH}$ and INDL QTLs with positive Gaspé Flint allelic effect were identified in the $\mathrm{BC}_{1}$ and $\mathrm{F}_{2}$ populations and not in the IL (Additional files 4 and 5). Such result was likely the consequence of the residual heterozygosity of the $\mathrm{BC}_{1}$ and $\mathrm{F}_{2}$ populations, which drove the expression of heterotic effects on PH and INDL.

By producing and testing IL lines with introgressions at two or more loci, epistatic interactions among QTLs can be addressed in a (statistically) powerful way $[39,40]$. Within the B73 $\times$ Gaspé Flint genetic background and for flowering traits, the presence of such interactions can be anticipated. The ND genetic effects of all Vgt QTLs under a fully additive mode summed to 14.7 nodes where the B73 - Gaspé Flint difference was 9.5 nodes; on the contrary Vgt QTL effects on DPS summed to 18.2 days, whereas the B73 - Gaspé Flint difference was 29.7 days. Such discrepancy is likely the consequence of multiple epistatic effects between different Vgt QTLs, which could reflect upon ND and DPS in different ways. However, additional causes could be (i) the segregation between B73 and Gaspé Flint of additional flowering loci lacking the strict ND-DPS pleiotropism and not represented within the IL, and (ii) the effect on the Gaspé Flint phenotypic mean value of a dominance component originated by the inherent Gaspé Flint heterozygosity.

\section{Molecular bases of flowering time}

This IL provides the opportunity to test the old hypothesis that the amount of nuclear DNA (C-value) influences flowering time. Maize genome size was shown to be negatively correlated with latitude and length of growing season $[41,42]$ and selection for earliness was linked with a reduction of C-values [43]. Similarly, a correlation was found between the presence of knobs (cytologically-detectable centromererelated chromosome regions, known to contain a large number of repeat units [44]) and delayed flowering time [45]. Gaspé Flint has been repeatedly shown to have one of the lowest $\mathrm{C}$-values among the genus Zea [46] and to carry the least number of knobs-resident DNA repetitive elements in comparison with other investigated inbreds [47].

A number of coincidences of Vgt QTLs with flowering time QTLs mapped in other studies were found. Vgt1$V g t 2$ and $q V g t-10.04 / 5$ coincided with two of the three highly recurrent consensus QTLs identified in a recent survey of 441 flowering time QTLs [48] and four $V g t$ QTLs (qVgt-1.05/6, Vgt1 and Vgt2, qVgt-9.03/4 an qVgt10.04/5) overlapped with 'hot-spot' QTLs identified after QTL meta-analysis [49]. Additionally, all the other $V g t$ QTLs mapped at regions of relatively high QTL density 
[47]. Part of the explanation for such coincidence is likely the redundant use of B73 and related inbred lines as parents in many experimental populations [48].

Beside Vgt1, no other Vgt locus has been resolved at the level of candidate sequence and/or QTN. However, evidence of genes possibly involved in flowering time and corresponding to Vgt loci (based on comparative and/or fine mapping) have been collected in at least four studies. An FT-like gene, ZCN8, co-mapping with Vgt2 (bin 8.04) was proposed as candidate based on the FT strict homology and pattern of expression profile [50]. Glossy15, an Ap2-like gene closely related with ZmRap2.7 and shown to regulate the juvenility traits and the time to flowering [51] co-maps with qVgt-9.03. qVgt-1.05/6 overlaps with bif2, a gene for which natural allelic variation has been correlated with flowering time and node number [52] and with an SPL-like gene implicated with flowering time in Arabidopsis [23]. The region of $q$ Vgt-10.04/5 harbors a photoperiod-sensitive locus shown to include a CTT-like gene homologous to a heading-date gene of rice [25].

\section{Genetics of adaptation to a short growing season environment}

Our results showed that the extreme earliness of Gaspé Flint, if compared to standard Corn Belt lines, is due to allelic variation at several loci, generally detected in other crosses [48], one of which (Vgt1, in this study linked with Vgt2) with sizeable effect. As a next step, it would be valuable to verify to what extent Gaspé Flint earliness is due to the combination of early alleles commonly present in the maize germplasm or to unique early alleles. The first hypothesis seems to be supported by the results obtained from the positional cloning of $V g t 1$, the major of such flowering time QTLs. At Vgt1, Gaspé has been shown to carry a relatively common haplotype, shared even by medium-late Corn Belt dent lines [22], tropical germplasms and teosintes [53]. Additionally, the coincidence of the Vgt QTLs with many other flowering time QTLs supports the notion that Gaspé Flint alleles are present in other genetic backgrounds. Therefore, Gaspé Flint could be the prototype of an unconscious QTL-allele pyramidization process, carried out by pre-Columbian, Native American farmers to adapt a tropical species to cultivation at the northern limit of the temperate zone by recruiting alleles for earliness at a number of loci. The importance of the molecular verification of such hypothesis cannot be overemphasized, since QTL pyramiding is at the core of the current genomics-assisted breeding paradigm [5].

Nonetheless, it is possible that mutations contributing new early alleles arose uniquely in the gene-pool under selection for earliness, and such mutations remained confined in the Northern Flints. Recurrent mutation at the sugary1 locus has already been shown to have occurred during the process that led to the release of modern sweet maize inbreds and cultivars [54]. A high mutation rate was also hypothesized to be responsible for the linear response to selection for flowering time, in a selection experiment starting from a small, highly inbred maize population [55]. Additionally, the extreme plasticity of the maize genome caused by the activity of transposable elements at coding as well as at intergenic regions $[56,57]$ makes it likely that changes at the regulatory region of flowering time genes could have caused early flowering, and could have recurrently been selected. Reinforcing this hypothesis, Gaspé Flint was already reported to show an unusually high rate of spontaneous mutations [58]. If confirmed, such high mutation rate could have provided the unique early alleles upon which selection for earliness acted.

The adaptation of maize, a tropical species, to the northern latitudes, and the molecular changes enabling it, can be set in a rather precise timeframe. Maize was domesticated from teosinte in the Balsas basin of southern Mexico ca. 6,000 - 10,000 years ago [59], then reached south western United States ca. 3,000 years ago and northern United States and Canada only 1,000 years ago, at the time when the very well-defined maize race group, the Northern Flint, originated $[18,60]$. The short early maize grown by the Penobscot Algonkins people in the Gaspé peninsula and described by the Canadian explorer Jacques Cartier in 1555 was likely Gaspé Flint [61]. The relatively late northward expansion of maize could have partially been caused by the complex genetic adaptations (e.g. extreme early flowering) required for the short growing season [18].

\section{Conclusions}

The genetic basis of maize flowering time was investigated using an introgression library developed using the virtually earliest maize cultivar, Gaspé Flint, and the elite reference inbred line B73. At least eight chromosome regions, including the well-known flowering time locus Vgt1, showed allelic variation influencing flowering time. These detected flowering time QTLs are involved in determining the number of vegetative phytomeres developed by the maize plant before switching to reproductive phase and do not appear to influence the rate of development (i.e.: plastochron/phyllochron). Thus, reducing the number of phytomeres seems to have been the key developmental feature enabling the adaptation of a tropical crop species like maize to much northern environments such as southern Canada. Thanks to the genetic constitution of the plant material (nearly isogenic lines) here described, all QTLs have been isogenized and are thus available for fine mapping. We anticipate that the availability of this introgression 
library will further contribute to the dissection and identification of the molecular bases of the rather impressive adapting plasticity of maize.

\section{Methods}

Plant material and production of the library

Gaspé Flint is an open-pollinated cultivar belonging to the Northern Flint germplasm race group [18] and characterized by extreme earliness, low stature, high tillering and multiple ears. Seed of Gaspé Flint was kindly donated by Ronald Phillips, University of Minnesota, St. Paul, USA. B73 is an elite inbred line belonging to the Iowa Stiff Stalk Synthetic heterotic group [62]. From the starting cross $\left(\mathrm{B} 73 \times\right.$ Gaspé Flint), two $\mathrm{F}_{1}$ plants were utilized in a backcross with B73. Following the production of $88 \mathrm{~B} 73 \times(\mathrm{B} 73 \times$ Gaspé Flint $) \mathrm{BC}_{1}$ plants, each plant was sampled for DNA extraction and profiled with 140 SSR markers (see below). Based on this molecular profiling, a set of heterozygous target chromosome regions (approximately one per $\mathrm{BC}_{1}$ plant), marked by two SSR flanking markers, were defined. From such plants, four additional generations of backcross using B73 as recurrent genotype were carried out, followed by three cycles of selfing. For each backcross or self generation and for each backcross family, approximately 20 plants were grown in the field and genotyped for the two markers flanking the target chromosome region. From $\mathrm{BC}_{2}$ to $\mathrm{BC}_{5}$, for each family, one plant (the one with more seed) heterozygous at the target region was advanced to the subsequent backcross generation. At the $\mathrm{BC}_{5}$ stage, plants heterozygous for the target introgression were selfed, producing $\mathrm{BC}_{5} \mathrm{~F}_{2}$ seed. Plants of each $\mathrm{BC}_{5} \mathrm{~F}_{2}$ family were screened with the assigned flanking SSR in order to identify and self plants (one per family) carrying the homozygous Gaspé Flint introgression. $\mathrm{BC}_{5} \mathrm{~F}_{3}$ families were then grown and selfed for seed increase and storage. The plants utilized for this experiment corresponded to $\mathrm{BC}_{5} \mathrm{~F}_{4}$ whereas available $\mathrm{IL}$ seed stocks correspond to $\mathrm{BC}_{5} \mathrm{~F}_{4}$ or $\mathrm{BC}_{5} \mathrm{~F}_{5}$.

\section{Marker analysis}

Genomic DNA was prepared from young leaf tissues as previously described [63]. A total of 180 SSR markers (Additional file 6) were utilized for searching polymorphisms between B73 and Gaspé Flint, 173 of which were informative and seven failed to do so. From the same set, SSR markers were selected for genotyping the IL. Primer information was downloaded from the Maize Genome Database at http://www.maizegdb.org. One additional marker, Vgt1-Mite, was utilized based on the information provided in [22]. PCR analyses for SSR were carried out as described [21] and separation and visualization followed standard agarose-gel electrophoresis protocols.

\section{Genome coverage and features of the IL}

Position for all markers as well as the length of chromosomes and introgressions are given in $\mathrm{cM}$ based on the maize reference map 'Genetic 2008' (available at http:// www.maizegdb.org/map.php). Coverage of the IL was computed by summing unique Gaspé introgressions across the IL. Introgression start- and end-points were taken as the mid-points from/to the nearest evaluated markers or the telomeres. The same approach was used to estimate the proportion of the Gaspé genome polymorphic with B73 and not represented in the library. Chromosome regions containing four or more adjacent monomorphic SSR markers were also similarly sized and considered technically non-representable (see Results).

\section{Production of the $F_{2}$ and $\mathrm{BC}_{1}$ populations and linkage maps}

Along with the IL, an $\mathrm{F}_{2}$ population and a $\mathrm{BC}_{1}$ population were produced and utilized for linkage map construction and QTL analysis. The 88 (B73 $\times$ Gaspé Flint) $\times \mathrm{B} 73 \mathrm{BC}_{1}$ plants corresponded to the ones used to establish the IL and were genotyped with 70 SSRs evenly spread on the 10 maize chromosome. Linkage map construction was carried out using JoinMap 3.0 [64], with a LOD threshold for linkage grouping of 3.0 and produced 10 linkage groups which covered $1278 \mathrm{cM}$ (71\% of the reference map). The $\mathrm{B} 73 \times$ Gaspé Flint $\mathrm{F}_{2}$ population included 65 plants and was genotyped with 26 polymorphic SSR markers covering maize chromosomes 1, 3, 8, 9 and 10. This linkage map covered $641 \mathrm{cM}$, corresponding to $78 \%$ of the same five linkage groups from the reference maize map 'Genetic 2008'. For the two maps, marker order was always in agreement with the one in the reference map.

\section{Field experiment and collection of phenotypic data}

All field experiments were carried out at the experimental station of the University of Bologna, near Cadriano

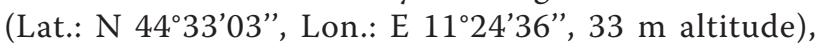
Italy. For the IL, 77 genotypes (75 IL lines, B73 and B73 $\times$ Gaspè Flint $F_{1}$ ) were planted following a randomized complete block design, with four repetitions. Gaspé Flint was grown in adjacent plots and not included in the IL experiment because its reduced stature and vigor would have biased the phenotypic score of neighbouring plots. The experiment was planted on April, 20, 2006, in 1.4 $\mathrm{m}$-long and $0.8 \mathrm{~m}$-wide single-row plots, with eight plants per row, for a final density of 6.25 plants $\mathrm{m}^{-2}$. Nine phenotypic traits were recorded or computed (Table 1): number of days from planting to pollen shed (DPS) measured when $50 \%$ of the plants in a plot had extruded at least one anther; number of ears (EARN) per plant counted at flowering; growing degree units (GDU) as alternative score for flowering time as 
described (Equation 1 in [65]); number of plant nodes (ND), measured as total number of leaves at flowering (the $6^{\text {th }}$ and $12^{\text {th }}$ leaves were marked to account for the early developed leaves not visible at flowering); number of nodes below the top ear (NDBE) were counted with reference to the $6^{\text {th }}$ and/or the $12^{\text {th }}$ marks, including the leaf (node) of the top ear; number of nodes above the top ear (NDAE) were computed as ND - NDBE; proportion of nodes below the ear (PNDBE) was computed as $\mathrm{NDBE} / \mathrm{ND}$; plant height $(\mathrm{PH})$ measured at the tip of the tassel; internode length (INDL) computed as the ratio $\mathrm{PH} / \mathrm{ND}$. The $\mathrm{F}_{2}$ population was grown contemporary and adjacent to the IL experiment, in plots of equal size. Phenotypic traits recorded or computed were the same as for the IL experiment. The $\mathrm{BC}_{1}$ population was planted on May 28, 2002, in $3 \mathrm{~m}$-long and $1 \mathrm{~m}$-wide plots, $0.2 \mathrm{~m}$ between plants (corresponding to 5 plants $\mathrm{m}^{-2}$ ). Phenotypic traits recorded or computed were DPS, EARN, GDU, INDL, ND and PH, as described for the IL experiment, while NDBE, NDAE and PNDBE were not considered.

\section{Phenotypic data and QTL analyses}

Normality of distribution for all trait values was tested by the Shapiro-Wilk test implemented in GenStat11 (VSN international Ltd, UK). For the IL data, ANOVA (Kruskall-Wallis for not normally distributed traits), phenotypic and genotypic correlations and heritability were computed using PLABSTAT version 3A [66]. IL line mean values for normally distributed traits (DPS, EARN, GDU, INDL, PH and PNDBE) were compared with the B73 mean values following a two-sided Dunnet's test as implemented in Statistica 8.0 (StatSoft, Inc.), with an alpha level of 0.05 , while for non-normally distributed traits (ND, NDBE and NDAE) a Steel's test was carried out as implemented in GenStat11. We additionally tested for the presence of a QTL in a given chromosome interval by means of a "bin mapping" approach where IL lines sharing the same introgression were grouped and the trait mean value tested against B73. Because in several cases the same introgression was shared by several lines, such test for the presence of a QTL was expected to have more statistical power than the simple comparison of each single line with B73. For normally distributed traits, bin mapping was carried out by a two-sided $t$-test, assuming unequal variance, as described in [9]. For the non-normally distributed traits, the non-parametric Mann-Whitney U-test was adopted instead. Both the $t$ - and the U-tests were carried out using GenStat11.

A QTL for a given trait was declared to correspond to a Gaspé Flint chromosome introgression (marked by SSR markers), when i) more than one IL line carrying such introgression significantly differed from B73 and no other Gaspè Flint introgression was shared by the same IL lines, or ii) a single IL line was significantly different from B73 and QTL evidence was obtained at the same chromosome region by the $\mathrm{BC}_{1}$ or the $\mathrm{F}_{2}$ QTL analyses with concordance of the genetic effect direction. In this case, correspondence was declared when the introgressed chromosome region and the 2-LOD support interval overlapped and the $F_{2}$ and/or the $\mathrm{BC}_{1}$ QTL LOD peak was included in the IL introgression region. The genetic effect for each QTL was computed as $\left(m_{I L L}-m_{B 73}\right) / 2$, were $m_{I L L}$ was the mean value for the IL line(s) with a given introgression and $\mathrm{m}_{\mathrm{B} 73}$ was the $\mathrm{B} 73$ value.

For the $\mathrm{BC}_{1}$ and the $\mathrm{F}_{2}$ datasets, QTL analyses was carried out using Composite Interval Mapping as implemented in PLABQTL [67]. The default cofactor selection parameters (cov SELECT option with a log of the likelihood (LOD) score of $>3.0$ to enter into the model) were used. The maps were scanned at 1-centimorgan (cM) intervals. LOD threshold for QTL significance $(P<$ $0.05)$ were obtained after 1,000 permutations and ranged from 2.94 for $\mathrm{PH}$ in the $\mathrm{F}_{2}$ population to 3.20 for $\mathrm{PNDBE}$ in the $\mathrm{BC}_{1}$ population. The reported genetic effects and the proportion of phenotypic variance explained (PVE) by each QTL were obtained after fitting a multi-QTL model with the 'final simultaneous fitting' routine. QTL positions (corresponding to relevant introgression regions identified in the IL experiment and to the 2-LOD drop supporting intervals computed for the $\mathrm{F}_{2}$ and $\mathrm{BC}_{1}$ populations) were projected using MapChart 2.2 [68] with $\mathrm{cM}$ distances based on the maize reference map 'Genetic 2008' available at http://www.maizegdb. org. QTL nomenclature followed rules proposed by [69].

\section{Additional material}

Additional file 1: Frequency distributions of the IL, $B C_{1}$ and $F_{2}$ populations for the analysed traits. This figure summarizes the frequency distribution for days to pollen shed (DPS), number of ears (EARN), growing degree units (GDU), internode length (INDL), number of nodes (ND), number of nodes below the top ear (NDBE), number of nodes above the ear (NDAE), plant height $(\mathrm{PH})$ and proportion of nodes below the ear (PNDBE), for the three populations under study.

Additional file 2: Table reporting the phenotypic correlations among traits based on the $\mathrm{B} 73 \times$ Gaspé Flint $\mathrm{BC}_{1}$ population. Additional file 3: Table reporting the phenotypic correlation among traits based on the $B 73 \times$ Gaspé Flint $F_{2}$ population.

Additional file 4: Table reporting the QTLs identified in the $\mathrm{B} 73 \times$ Gaspé Flint $\mathrm{BC}_{1}$ population.

Additional file 5: Table reporting the QTLs identified in the B73 $\times$ Gaspé Flint $F_{2}$ population.

Additional file 6: Table reporting the SSR markers (and relative positions) screened for polymorphism between B73 and Gaspé Flint. 


\section{Acknowledgements}

We thank Ronald Phillips for providing seed of Gaspé Flint and Matteo Ferri, Stefano Vecchi and Elena Govoni for technical support. We thank Francesca Ventura for providing meteorological data (temperature) for the GDU analysis. We acknowledge the contribution of the Interdepartmental Centre for Biotechnology, University of Bologna.

\section{Author details}

'Department of Agroenvironmental Sciences and Technologies, University of Bologna, viale Fanin 44, 40127 Bologna, Italy. ${ }^{2}$ Department of Horticulture and Landscape Architecture, 625 Agriculture Mall Drive, Purdue University, West Lafayette, IN 47907, USA

\section{Authors' contributions}

SS conceived the study, participated to the field and molecular work and drafted the manuscript; CSimona, BM, CN, CSara performed field and molecular work and participated to statistical analyses; SMC supervised field experiment design and performed statistical analysis; TR participated in conceiving the study, coordinating the field and molecular work and in drafting the manuscript. All authors read and approved the final manuscript.

Received: 4 June 2010 Accepted: 6 January 2011

Published: 6 January 2011

\section{References}

1. Thoday J: Location of polygenes. Nature 1961, 191:368-370.

2. Wehrhahn C, Allard R: The detection and measurements of the effects of individual genes involved in the inheritance of a quantitative character in wheat. Genetics 1965, 51:109-119.

3. Eshed Y, Zamir D: An introgression line population of Lycopersicon pennellii in the cultivated tomato enables the identification and fine mapping of yield-associated QTL. Genetics 1995, 141(3):1147-1162.

4. Zamir D: Improving plant breeding with exotic genetic libraries. Nat Rev Genet 2001, 2(12):983-989.

5. Grandillo S, Tanksley S, Zamir D: Exploitation of natural biodiversity through genomics. In Genomics-Assisted Crop Improvement: Genomics Approaches and Platforms. Edited by: Varshney RK, Tuberosa R. New York: Springer; 2007:121-150

6. Keurentjes JJB, Bentsink L, Alonso-Blanco C, Hanhart CJ, Vries HBD, Effgen S, Vreugdenhil D, Koornneef M: Development of a near-isogenic line population of Arabidopsis thaliana and comparison of mapping power with a recombinant inbred line population. Genetics 2007, 175(2):891-905.

7. Schmalenbach I, Korber N, Pillen K: Selecting a set of wild barley introgression lines and verification of QTL effects for resistance to powdery mildew and leaf rust. Theor Appl Genet 2008, 117(7):1093-1106.

8. Takada T, Mita A, Maeno A, Sakai T, Shitara H, Kikkawa Y, Moriwaki K, Yonekawa $\mathrm{H}$, Shiroishi T: Mouse inter-subspecific consomic strains for genetic dissection of quantitative complex traits. Genome Res 2008 , 18(3):500-508.

9. Doroszuk A, Snoek LB, Fradin E, Riksen J, Kammenga J: A genome-wide library of CB4856/N2 introgression lines of Caenorhabditis elegans. Nucleic Acids Res 2009, 37(16)

10. Torjek O, Meyer RC, Zehnsdorf M, Teltow M, Strompen G, Witucka-Wall H, Blacha A, Altmann T: Construction and analysis of 2 reciprocal Arabidopsis introgression line populations. J Hered 2008, 99(4):396-406.

11. Szalma SJ, Hostert BM, LeDeaux JR, Stuber CW, Holland JB: QTL mapping with near-isogenic lines in maize. Theor Appl Genet 2007. 114(7):1211-1228.

12. Saha S, Jenkins JN, Wu JX, McCarty JC, Gutierrez OA, Percy RG, Cantrell RG, Stelly DM: Effects of chromosome-specific introgression in upland cotton on fiber and agronomic traits. Genetics 2006, 172(3):1927-1938

13. Stuber CW, Polacco M, Lynn M: Synergy of empirical breeding, markerassisted selection, and genomics to increase crop yield potential. Crop Sci 1999, 39(6):1571-1583.

14. Ashikari M, Matsuoka M: Identification, isolation and pyramiding of quantitative trait loci for rice breeding. Trends Plant Sci 2006, 11(7):344-350

15. Lippman ZB, Semel Y, Zamir D: An integrated view of quantitative trait variation using tomato interspecific introgression lines. Curr Opin Genet \& Dev 2007, 17(6):545-552.
16. Frary A, Nesbitt TC, Grandillo S, van der Knaap E, Cong B, Liu JP, Meller J, Elber R, Alpert KB, Tanksley SD: fw2.2: A quantitative trait locus key to the evolution of tomato fruit size. Science 2000, 289(5476):85-88.

17. Fridman E, Pleban T, Zamir D: A recombination hotspot delimits a wildspecies quantitative trait locus for tomato sugar content to $484 \mathrm{bp}$ within an invertase gene. Proc Natl Acad Sci USA 2000, 97(9):4718-4723.

18. Vigouroux Y, Glaubitz JC, Matsuoka Y, Goodman MM, Jesus SG, Doebley J: Population structure and genetic diversity of new world maize races assessed by DNA microsatellites. Am J Bot 2008, 95(10):1240-1253.

19. Goodman MM, Brown WL: Races of corn. In Corn and corn improvement. 3 edition. Edited by: Sprague GF, Dudley JW. Madison: American Society of Agronomy; 1988:33-79.

20. Vladutu C, MCLaughlin J, Phillips RL: Fine mapping and characterization of linked quantitative trait loci involved in the transition of the maize apical meristem from vegetative to generative structures. Genetics 1999 153(2):993-1007.

21. Salvi $S$, Tuberosa $R$, Chiapparino E, Maccaferri M, Veillet $S$, van Beuningen $L$, Isaac P, Edwards K, Phillips RL: Toward positional cloning of Vgt1, a QTL controlling the transition from the vegetative to the reproductive phase in maize. Plant Mol Biol 2002, 48(5):601-613.

22. Salvi S, Sponza G, Morgante M, Tomes D, Niu X, Fengler K, Meeley R, Ananiev E, Svitashev S, Bruggemann E, Niu X, Li B, Rafalski A, Tingey SV, Miao G-H, Phillips RL, Tomes D, Tuberosa R: Conserved noncoding genomic sequences associated with a flowering-time quantitative trait locus in maize. Proc Natl Acad Sci USA 2007, 104(27):11376-11381.

23. Lauter N, Moscou M, Habiger J, Moose S: Quantitative genetic dissection of shoot architecture traits in maize: towards a functional genomics approach. Plant Genome 2008, 1:99-110.

24. Coles ND, McMullen MD, Balint-Kurti PJ, Pratt RC, Holland JB: Genetic control of photoperiod sensitivity in maize revealed by joint multiple population analysis. Genetics 2010, 184(3):799-812

25. Ducrocq S, Giauffret C, Madur D, Combes V, Dumas F, Jouanne $S$, Coubriche D, Jamin P, Moreau L, Charcosset A: Fine mapping and haplotype structure analysis of a major flowering time quantitative trait locus on maize chromosome 10. Genetics 2009, 183(4):1555-1563.

26. Wang $\mathrm{CL}$, Cheng FF, Sun ZH, Tang JH, Wu LC, Ku LX, Chen YH: Genetic analysis of photoperiod sensitivity in a tropical by temperate maize recombinant inbred population using molecular markers. Theor Appl Genet 2008, 117(7):1129-1139.

27. Neuffer MG, Coe EH, Wessler SR: Mutants of maize New York: Cold Spring Harbour Laboratory Press; 1997

28. Buckler ES, Holland JB, Bradbury PJ, Acharya CB, Brown PJ, Browne C Ersoz E, Flint-Garcia S, Garcia A, Glaubitz JC, Goodman MM, Harjes C, Guill K, Kroon DE, Larsson S, Lepak NK, Li HH, Mitchell SE, Pressoir G, Peiffer JA, Rosas MO, Rocheford TR, Romay MC, Romero S, Salvo S, Villeda HS, Da Silva HS, Sun Q, Tian F, Upadyayula N, Ware D, Yates H, Yu JM, Zhang ZW Kresovich S, McMullen MD: The genetic architecture of maize flowering time. Science 2009, 325(5941):714-718.

29. Schnable PS, Ware D, Fulton RS, Stein JC, Wei F, Pasternak S, Liang C, Zhang J, Fulton $L$, et al: The B73 maize genome: complexity, diversity, and dynamics. Science 2009, 326(5956):1112-1115.

30. Salvi S, Tuberosa R: To clone or not to clone plant QTLs: present and future challenges. Trends Plant Sci 2005, 10(6):297-304

31. Tuberosa R, Salvi S, Sanguineti MC, Landi P, Maccaferri M, Conti S: Mapping QTLs regulating morpho-physiological traits and yield in droughtstressed maize: case studies, shortcomings and perspectives. Ann Bot 2002, 89(7):941-963.

32. Chuck G, Cigan AM, Saeteurn K, Hake S: The heterochronic maize mutant Corngrass 1 results from overexpression of a tandem microRNA. Nat Genet 2007, 39(4):544-549.

33. Kawakatsu T, Taramino G, Itoh J, Allen J, Sato Y, Hong SK, Yule R, Nagasawa N, Kojima M, Kusaba M, Sakakibara H, Sakai H, Nagato Y: PLASTOCHRON3/GOLIATH encodes a glutamate carboxypeptidase required for proper development in rice. Plant J 2009, 58(6):1028-1040.

34. Shimizu-Sato S, Tanaka M, Mori H: Auxin-cytokinin interactions in the control of shoot branching. Plant Mol Biol 2009, 69(4):429-435.

35. Ragot M, Sisco PH, Hoisington DA, Stuber CW: Molecular-marker-mediated characterization of favorable exotic alleles at quantitative trait loci in maize. Crop Sci 1995, 35(5):1306-1315. 
36. Gallavotti A, Zhao Q, Kyozuka J, Meeley RB, Ritter M, Doebley JF, Pe ME, Schmidt RJ: The role of barren stalk1 in the architecture of maize. Nature 2004, 432(7017):630-635

37. Shaver D: Genetics and breeding of maize with extra leaves above the ear. 38th Annual Corn and Sorghum Research Conference: 7-8 Dec. 1983 Washington, DC: American Seed Trade Association; 1983, 161-180.

38. Winkler RG, Helentjaris T: The maize Dwarf3 gene encodes a cytochrome p450-mediated early step in gibberellin biosynthesis. Plant Cell 1995, 7(8):1307-1317.

39. Melchinger AE, Piepho HP, Utz HF, Muminovic J, Wegenast T, Torjek O, Altmann T, Kusterer B: Genetic basis of heterosis for growth-related traits in Arabidopsis investigated by testcross progenies of near-isogenic lines reveals a significant role of epistasis. Genetics 2007, 177(3):1827-1837.

40. Reif JC, Kusterer B, Piepho HP, Meyer RC, Altmann T, Schon CC, Melchinger AE: Unraveling epistasis with triple testcross progenies of near-isogenic lines. Genetics 2009, 181(1):247-257.

41. Laurie DA, Bennett MD: Nuclear-DNA content in the genera Zea and Sorghum - intergeneric, interspecific and intraspecific variation. Heredity 1985, 55:307-313.

42. Rayburn AL, Price HJ, Smith JD, Gold JR: C-band heterochromatin and DNA content in Zea mays. Am J Bot 1985, 72(10):1610-1617.

43. Rayburn AL, Dudley JW, Biradar DP: Selection for early flowering results in simultaneous selection for reduced nuclear DNA content in maize. Plant Breed 1994, 112(4):318-322.

44. Dawe R: Maize centromeres and knobs (neocentromeres). In Maize Handbook Volume II Genetics and Genomics. Edited by: Bennetzen J, Hake S. New York: Springer; 2009.

45. Chughtai SR, Steffensen DM: Heterochromatic knob composition of commercial inbred lines of maize. Maydica 1987, 32(3):171-187.

46. Grant WF, Owens ET: Zea mays assays of chemical/radiation genotoxicity for the study of environmental mutagens. Mutat Res Rev Mutat Res 2006 613(1):17-64

47. Ananiev EV, Phillips RL, Rines HW: Complex structure of knob DNA on maize chromosome 9: Retrotransposon invasion into heterochromatin. Genetics 1998, 149(4):2025-2037.

48. Salvi S, Castelletti S, Tuberosa R: An updated consensus map for flowering time QTLs in maize. Maydica 2009, 54:501-512.

49. Chardon F, Virlon B, Moreau L, Falque M, Joets J, Decousset L, Murigneux A Charcosset A: Genetic architecture of flowering time in maize as inferred from quantitative trait loci meta-analysis and synteny conservation with the rice genome. Genetics 2004, 168(4):2169-2185.

50. Danilevskaya ON, Meng X, Hou ZL, Ananiev EV, Simmons CR: A genomic and expression compendium of the expanded PEBP gene family from maize. Plant Physiol 2008, 146(1):250-264.

51. Lauter N, Kampani A, Carlson S, Goebel M, Moose SP. microRNA172 downregulates glossy15 to promote vegetative phase change in maize. Proc Natl Acad Sci USA 2005, 102(26):9412-9417.

52. Pressoir G, Brown PJ, Zhu WY, Upadyayula N, Rocheford T, Buckler ES Kresovich S: Natural variation in maize architecture is mediated by allelic differences at the PINOID co-ortholog barren inflorescence2. Plant J 2009, 58(4):618-628

53. Ducroca S, Madur D, Veyrieras JB, Camus-Kulandaivelu L, Kloiber-Maitz M, Presterl T, Ouzunova M, Manicacci D, Charcosset A: Key impact of Vgt1 on flowering time adaptation in maize: Evidence from association mapping and ecogeographical information. Genetics 2008, 178(4):2433-2437.

54. Tracy WF, Whitt SR, Buckler ES: Recurrent mutation and genome evolution: example of Sugary 1 and the origin of sweet maize. Crop Sci 2006, 46(S1):S-49-S-54

55. Durand $\mathrm{E}$, Tenaillon $\mathrm{M}$, Ridel $\mathrm{C}$, Coubriche $\mathrm{D}$, Jamin $\mathrm{P}$, Jouanne $\mathrm{S}$, Ressayre A, Charcosset A, Dillmann C: Standing variation and new mutations both contribute to a fast response to selection for flowering time in maize inbreds. BMC Evol Biol 2010, 10:2

56. Morgante M, Brunner S, Pea G, Fengler K, Zuccolo A, Rafalski A: Gene duplication and exon shuffling by helitron-like transposons generate intraspecies diversity in maize. Nat Genet 2005, 37(9):997-1002.

57. Wang $\mathrm{QH}$, Dooner HK: Remarkable variation in maize genome structure inferred from haplotype diversity at the bz locus. Proc Natl Acad Sci USA 2006, 103(47):17644-17649.

58. Vladutu Cl, Phillips RL: Spontaneous activation of transposable elements following an interracial cross in maize. Maize Genetics Cooperation Newsletter 1998, 72:70-71
59. Matsuoka Y, Vigouroux Y, Goodman MM, Sanchez GJ, Buckler E, Doebley J: A single domestication for maize shown by multilocus microsatellite genotyping. Proc Natl Acad Sci USA 2002, 99(9):6080-6084.

60. Fritz GJ: New dates and data on early agriculture - The legacy of complex hunter-gatherers. Ann Miss Bot Gard 1995, 82(1):3-15.

61. Byers D: Review of "The Native Americans: Prehistory and Ethnology of the North American Indians" by Spencer RF and Jennings JD. Am Antiquity 1966, 31:582-584.

62. Gerdes JT, Behr CF, Coors JG, Tracy WF: In Compilation of North American Maize Breeding Germplasm. Edited by: Tracy WF, Coors JG, Geadelmann JL. Madison: Crop Science Society of America; 1993.

63. Salvi S, Phillips RL, Tuberosa R: Development of PCR-based assays for allelic discrimination in maize by using the $5^{\prime}$-nuclease procedure. $\mathrm{Mol}$ Breed 2001, 8(2):169-176.

64. Van Ooijen J, Voorrips R: Join Map ${ }^{\oplus} 3.0$, Software for the calculation of genetic linkage maps. Plant Research International, Wageningen, the Netherlands; 2001

65. Dwyer LM, Stewart DW, Carrigan L, Ma BL, Neave P, Balchin D: Guidelines for comparisons among different maize maturity rating systems. Agron J 1999, 91(6):946-949.

66. Utz HF: PLABSTAT: a computer program for the statistical analysis of plant breeding experiments. University of Hohenheim, Stuttgart, Germany: Institute of Plant Breeding, Seed Science and Population Genetics; 1998.

67. Utz HF, Melchinger AE: PLABQTL: A program for composite interval mapping of QTL. J Quant Trait Loci 1996, 2(1)

68. Voorrips RE: MapChart: Software for the graphical presentation of linkage maps and QTLs. J Hered 2002, 93(1):77-78.

69. McCouch S, Cho Y, Yano M, Paul E, Blinstrub M, Morishima H, Kinoshita T: Report on OTL nomenclature. Rice Genetics Newsletter 1997, 14:11-13.

doi:10.1186/1471-2229-11-4

Cite this article as: Salvi et al:: Genetic dissection of maize phenology using an intraspecific introgression library. BMC Plant Biology 2011 11:4

\section{Submit your next manuscript to BioMed Central and take full advantage of:}

- Convenient online submission

- Thorough peer review

- No space constraints or color figure charges

- Immediate publication on acceptance

- Inclusion in PubMed, CAS, Scopus and Google Scholar

- Research which is freely available for redistribution

Submit your manuscript at www biomedcentral com/submit
C Biomed Central 